\title{
Peritoneal Patch Used for Vascular Reconstruction of the Superior Mesenteric Vein Invaded by Locally Advanced Pancreatic Tumour
}

\author{
Mehmet Tahir Oruç, Tuğrul Çakır, Arif Aslaner, Erdem Can Yardımcı, Alkan Sakar
}

General Surgery Department, Antalya Training and Research Hospital, Muratpașa, Antalya, Turkey

\section{ABSTRACT}

Various options are available as sources of autologous veins for vascular reconstruction in cases of vascular injury or venous vascular invasion of solid tumours. However, in such cases, the time spent preparing the autologous vein graftas well asthe associated morbidities of the donor region influence the postoperative course. We present the first case of peritoneal patch utilisation in order to re-establish the vascular continuity after superior mesenteric vein (SMV) resection due to pancreatic tumour invasion, in a 57-year-old man. If prosthetic material is considered, an increased risk of infection, as well as its relative paucity in some centres both have to be taken into consideration. Especially in emergency conditions and perceived perioperative vascular invasion of solid tumours, parietal peritoneum can easily be prepared and used as an available option for autologous vein or prosthetic material. Autologous peritoneum grafts can be used especially in emergency conditions, in cases of venous invasion of solid organ tumours and in major vascular injuries when vascular reconstruction with primary suture is not possible. It can easily be prepared at the required size and shape, it is safe to use and cost effective.

Key words: peritoneal patch, pancreas tumour, superior mesenteric vein, autologous graft

\section{INTRODUCTION}

When reconstruction of the portal vein or the SMV after tumour resection is needed, autologous veins or synthetic materials are usually used as a patch or tube graft. However, the time spent for autologous vein removal with an extra incision as well as the intraoperative contamination of the synthetic graft both affect the postoperative morbidity $(1,2)$. In such cases, a peritoneal patch can be easily prepared and utilised in vascular reconstruction, without additional prolongation of the operative time or need for expert surgical input. In our case, because of a lack of synthetic grafts in our hospital and in order to avoid prolonging the operative time by preparing a venous autologous graft, a peritoneal patch was used. This consisted of a $2 \times 2 \mathrm{~cm}$ parachute-shaped patch which was removed by diathermy from the abdominal peritoneum and was subsequently used to swiftly re-establish the continuity of the SMV.

\section{Corresponding author:}

Arif Aslaner, Chief Assistant of General Surgery Department, Antalya Training and Research Hospital, Muratpașa, Antalya, Turkey

E-mail: arifaslaner@gmail.com
Received: 1.11.2017

Accepted: 10.11.2017

Copyright $(\odot$ Celsius Publishing House www.jtmr.ro 


\section{CASE REPORT}

A 57-year-old man presented to our clinic with jaundice and abdominal swelling and a positive Courvoisier-Terrier's sign.

The trans-abdominal ultrasonography revealed a 35$\mathrm{mm}$ hypoechoic solid lesion located in the pancreatic head; no invasion of major vascular axes could be ascertained. In addition, his dynamic abdominal computed tomography scanshowed a distended gallbladder, the common bile duct dilated to $18 \mathrm{~mm}$ at the widest point, and a hypodense mass (measuring $30 \times 20 \mathrm{~mm}$ ) located in the pancreatic head. However, no invasion of any of the following was observed: the portal vein, hepatic artery, superior mesenteric vein and superior mesenteric artery (fig. 1). The MRCP study showed a dilated pancreatic duct due to a stricture in the pancreatic head. Both the intrahepatic bile ducts as well as the common bile duct (CBD) were dilated. The PET-CT imaging revealed a mass $(43 \times 36 \times 32 \mathrm{~mm})$ with central cystic changes located in the pancreatic head, with an increased FDG uptake in peripheral nerves (SUV max: 4.5). A diffuse fat stranding was also observed in the mesenteric fatty tissues surrounding the mass, as well as focal densities with the largest one measuring 1 $\mathrm{cm}$ in diameter, suggesting invaded loco-regional lymph nodes as well as local extension of the tumour.

The preoperative workup revealed the following results: Amylase 30, lipase: 5, total bilirubin: 8.6, d. bilirubin: 5.01 CA 19.9: 2104.7 CEA:N CA 15.3:N CA125:N AFP:N.

Intraoperatively, a $3 \times 3 \mathrm{~cm}$ palpable hard mass with malignant appearance was noted in the head of the pancreas; at this time the invasion of the SMV also became apparent. The tumour was assessed as being resectable and a pancreaticoduodenectomy en bloc with the invaded portion of the SMV was performed.

The reconstruction of the SMV was performed using a $2 \times 2 \mathrm{~cm}$ patch of parietal peritoneum, which was resected widely in an oblique fashion from the right subcostal region. The defect of the SMV, which was 20 $\mathrm{mm}$ in length and $7 \mathrm{~mm}$ in width, was reconstructed using the wide peritoneal patch, with a continuous 6-0 prolene suture (fig. 2). The patient was givena single dose (5000 IU) of i.v. heparin intraoperatively, followed by postoperative Enoxaparin Sodium therapy at a dose of 4000 anti-XA IU (0.4 ml) s.c., which was discontinued on postoperative day (POD) 9. The pathology report of resected specimens confirmed a tumour invasion of the SMV. On POD 7, warfarin sodium therapy $(5 \mathrm{mg} /$ day) was added to the anticoagulant medication regimen. Surgery time was 215 minutes and no postoperative

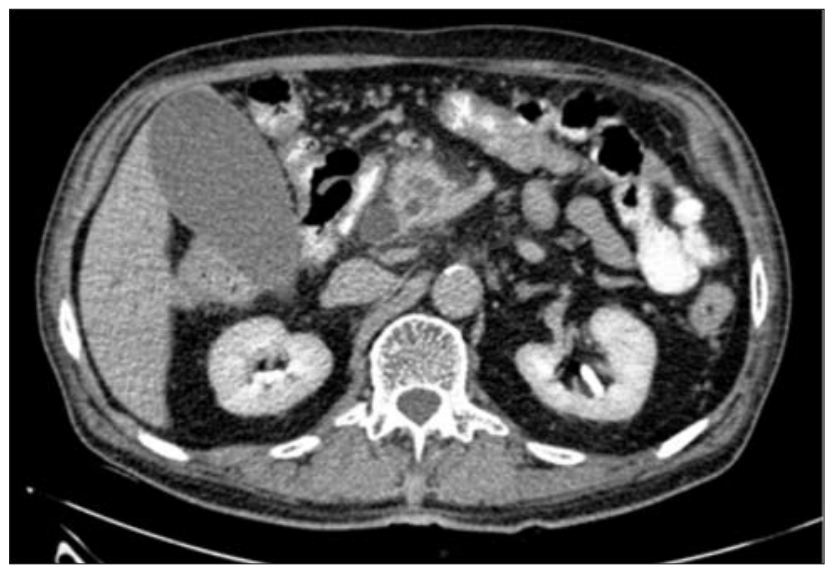

Figure 1 - Abdominal CT scan showing a hypodense mass in the pancreatic head and distended gallbladder

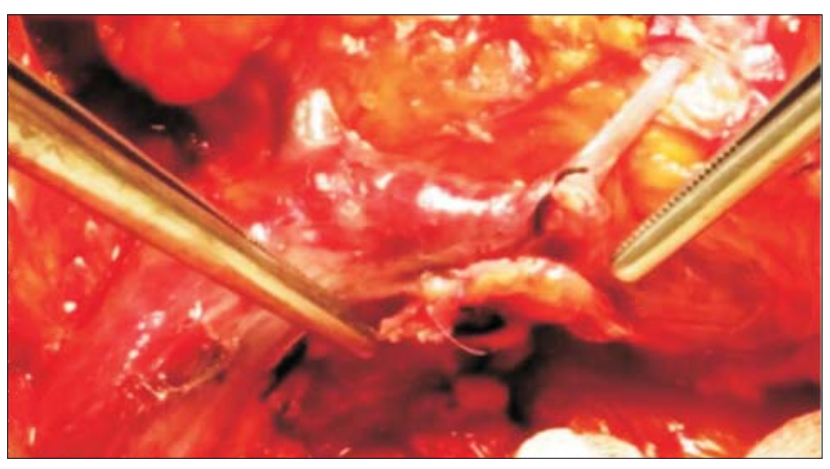

Figure 2 - Reconstruction of defect on the SMV by using a peritoneal patch, intraoperative image

bleeding occurred. During the postoperative analgesia paracetamol infusion were used. The patient was discharged on POD 9 completely recovered. A follow-up $\mathrm{CT}$ angiography revealed a patent and normal appearing superior mesenteric vein (fig. 3).

\section{DISCUSSION}

Vascular repair options are rather limited in cases of venous resection due to malignancy or trauma-related injuries of great vessels. In such cases, an experienced surgeon, with the appropriate equipment at his disposal, may provide significant advantages for the patient. Clinical decision making that takes into account the availability of various equipment in the hospital where the operation will take place is of vital importance for the patient as well as the surgeon.

Vascular reconstruction after major vascular resections employs autologous, allogeneic or synthetic grafts. In our case, the patient had undergone coronary bypass surgery 6 years ago, which was performed using the patient's right great saphenous vein. Thus, we decided 


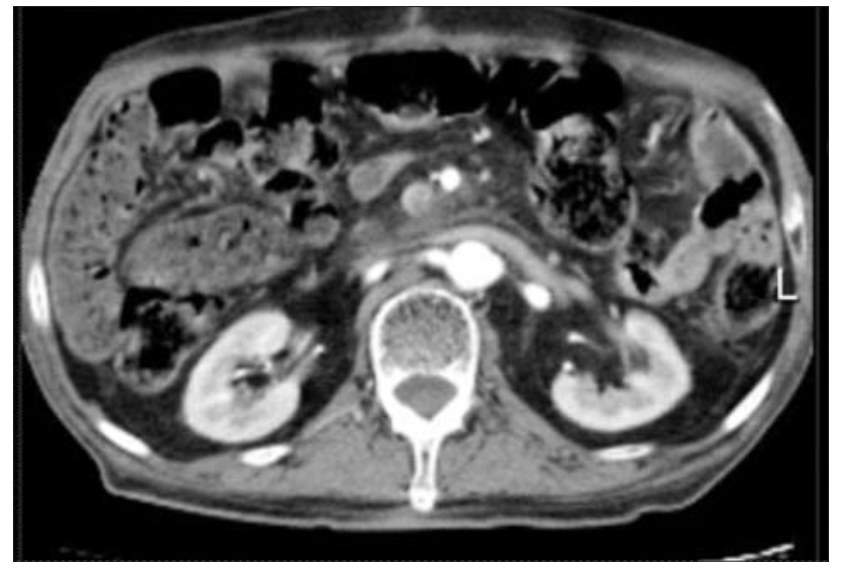

Figure 3 - Postoperative sixth month CT angiography showing intact SMV

not to waste additional time preparing an autologous graft. Preparing an autologous graft requires experience in such procedures, and the morbidity of the related area affects the postoperative morbidity. As our clinic had no synthetic grafts or cryopreserved vascular graft bank, we decided to use a peritoneal graft. After the peritoneal patch was retrieved from the right subcostal region, it was sutured into the defect in the superior mesenteric vein and then anastomosed to the portal vein in order to allow portal flow into the systemic circulation without any delay. As the patient's right great saphenous vein had been used during a previous coronary bypass surgery, we chose not to use a saphenous vein in order to save it for any possible cardiac pathology in the future.

The most common synthetic grafts used in vascular reconstruction, polytetrafluoroethylene (PTFE) grafts, have been shown to have a good patency rate of $80 \%$, especially in areas with lower blood flow and low venous pressure. However, the lack of experience in the use of this material may lead to practical difficulties, because it has a relatively rigid structure in comparison to autologous materials. Moreover, PTFE grafts are prone to bleeding due to leaks occurring through suture holes, especially in patients with ableeding diathesis. In such cases, autologous venous grafts may be derived from the large saphenous vein, internal jugular vein, basilic and cephalic veins.

Autologous grafts can present endothelial damage due to fibrotic valves, varicose veins, atherosclerotic wall structure, subsequently adversely influencing vascular patency. The peritoneal mesothelium, on the other hand, has certain advantages, such as compliance with native vasculature and facilitating migration of native cells (3).

The fact that vascular defects can be successfully repaired with a patch derived from the peritoneum was first demonstrated by the French surgeon Alexis Carrel in 1910 (4). Experimental studies have showed that peritoneal patches used in vascular surgery are covered with endothelial cells within two weeks (5). The comparison of autologous and synthetic grafts used in vascular surgery in terms of susceptibility to infection and thrombosis has revealed that autologous grafts are associated with a lower risk of infection and thrombosis (6-9). The use of synthetic grafts should be avoided in cases of contaminated injuries caused by penetrating trauma, chiefly because of an increased risk of infection (10). A case report concerning a living-donor liver transplant recipient showed that a peritoneal patch was used during the hepatectomy to prevent stricture development in the left hepatic vein, with no thrombosis observed within a 5-year follow-up period (11). Furthermore, some experimental studies demonstrated that peritoneal grafts caused no thrombosis, despite the fact that patients did not receive any antithrombotic therapy (12).

\section{CONCLUSIONS}

In conclusion, an autologous peritoneal patch appears to be a relatively better alternative in cases requiring vascular reconstruction after major vascular injuries as well as after resection of tumours with vascular invasion where primary suture is unachievable. The peritoneal patch is both technically undemanding to harvest in the preferred size and easy to handle. Besides, it is available at low cost and has a relatively lower risk of infection and thrombosis in comparison to other alternatives.

More importantly, autologous peritoneal patch is the only safe and practical option for surgeons encountering such cases in centres without synthetic vascular grafts or a cryopreserved vascular graft bank.

Acknowledgments: None

Sources of funding: None

Conflict of interest: None

\section{REFERENCES}

1. Ribbe EB, Alm P, Hallberg L. Peritoneal tube grafts, PTFE grafts and vein grafts in the inferior vena cava of the rat-a light microscopical and scanning electron microscopical study. Surg Res Commun. 1987;2:43-57.

2. Verhagen HJ, Blankensteijn JD, de Groot PG, Heijnen-Snyder GJ, Pronk A, Vroom TM, et al. In vivo experiments with mesothelial cell seeded ePTFE vascular grafts. Eur J Vasc Endovasc Surg. 
1998;15(6):489-96.

3. Robert W. Hoson II, Samuel E. Wilson, Frank J. Veith. Vascular surgery principles and practice. New York: 1987.

4. Carrel A. Peritoneal patching of the aorta. J Exp Med. 1910; 12(2):139-45

5. Yoshioka M, Onda M, Tajiri T, Akimaru K, Mineta S, Hirakata A, et al. Reconstruction of the portal vein using a peritoneal patch-graft. Am J Surg. 2001;181(3):247-50.

6. Takayama Y, Kanamaru H, Yokoyama H, Hashimoto H, Yoshino G, Toyoda $\mathrm{H}$, et al. Portal vein reconstruction using an internal jugular vein as a graft: report of a case. Surg Today. 1995;25(4): 378-80.

7. Cronenweit JL. Arterial aneurysms. In: Rutherford RB. Rutherford Vascular Surgery. 6th ed. Philadelphia: Elsevier Saunders; 2005. p. 475-88.

8. Emmiler M, Kocogullari CU, Yilmaz S, Cekirdekci A. Repair of the inferior vena cava with autogenous peritoneo-fascial patch graft following abdominal trauma: a case report. Vasc Endovascular Surg. 2008;42(3):272-5. doi: 10.1177/1538574407311604.

9. Akimaru K, Onda M, Tajiri T, Yoshida H, Yokomuro S, Mamada Y, et al. Middle hepatic vein reconstruction using a peritoneal patch: report of a case. Surg Today. 2002;32(1):75-7.

10. Ribbe EB, Alm P, Hallberg E, Norgren LE. Evaluation of peritoneal tube grafts in the inferior vena cava of the pig. Br J Surg. 1988;75(4):35760.

11. Yilmaz S, Kayaalp C, Battaloglu B, Ersan V, Ozgor D, Piskin T. Hepatic vein stenosis developed during living donor hepatectomy and corrected with peritoneal patch technique: a case report. Transplant Proc. 2012;44(6):1754-6. doi: 10.1016/j.transproceed.2012.05.034.

12. Yoshioka M, Onda M, Tajiri T, Akimaru K, Mineta S, Hirakata A, et al. Reconstruction of the portal vein using a peritoneal patch-graft. Am J Surg. 2001;181(3):247-50. 